\title{
Special topical issue: karst waters of Europe
}

\author{
James W. LaMoreaux ${ }^{1}$
}

Accepted: 26 October 2016/Published online: 8 November 2016

(c) Springer-Verlag Berlin Heidelberg 2016

Karst aquifers cover about $15 \%$ of the earth's surface, but supply about $25 \%$ of the earth's useful water. In Europe, these karst water resources play crucial roles. The continuing use of these karst water resources, together with the inherent characteristics of karst systems, requires special monitoring of water quality and land use activities to preserve and protect these important water supply systems.

In Besancon, France in September 2011, a special meeting of the H2Karst Conference was held. A diversity of problems and approaches in European karst were discussed. Under the direction of the Scientific Committee and spearheaded by Dr. Jacques Mudry, Dr. Catherine Bertrand, and Dr. Francois Zwahlen, selected authors from this meeting and other scientists were then invited to participate in the presentation of a special separate issue for the journal Carbonates and Evaporites on the Karst Waters of Europe.

The current volume contains selected results of this important work. The ongoing conference series which was the original impetus for this special series plans to meet in 2016 in Neuchatel, Switzerland, and then again in 2018 in Besancon, France, and in 2020 in Malaga, Spain under the name Eurokarst.

James W. LaMoreaux

jlamoreaux@pela.com

1 Tuscaloosa, AL, USA 